\title{
Compressibility of carbon fabrics with needleless electrospun PAN nanofibrous interleaves
}

\author{
S. V. Lomov ${ }^{1 *}$, K. Molnár $r^{2,3}$ \\ ${ }^{1}$ Department of Materials Engineering, KU Leuven, Kasteelpark Arenberg 44, 3001 Leuven, Belgium \\ ${ }^{2}$ Department of Polymer Engineering, Faculty of Mechanical Engineering, Budapest University of Technology and \\ Economics, Müegyetem rkp. 3., H-1111, Budapest, Hungary \\ ${ }^{3}$ MTA-BME Research Group for Composite Science and Technology, Müegyetem rkp. 3., H-1111, Budapest, Hungary
}

Received 7 April 2015; accepted in revised form 16 August 2015

\begin{abstract}
The present paper investigates how the presence of nanofiber interleaves affects the compressibility of the layup during manufacturing of the composites and hence determining the theoretically attainable fiber volume fraction at the given processing pressure. The results show that up to the interleave areal density of $10 \mathrm{~g} / \mathrm{m}^{2}$ per nanofiber layer the decrease of fiber volume fraction does not exceed $3 \%$ for a laminate of carbon fiber woven fabric. Interleaves inside a fabric laminate are more compressible than a plain electrospun veil. It can be explained as the nanofibers penetrate between the carbon fibers when applying compression during composite manufacturing. It can be stated that there is a strong interference between the interleaves and the carbon reinforcement, which can lead to effective toughness improvement of the composite without significant alteration of fiber volume content.
\end{abstract}

Keywords: polymer composites, needleless electrospinning, carbon fiber, nanofiber, compressibility

\section{Introduction}

Electrospinning is a simple and popular method for producing different nanofiber structures, fiber mats are the most common format. These nanofiber webs can have several applications, including medical [13], pharmaceutical [4, 5], sensor [6], filtering [7-9], clothing, construction engineering applications as well as composites $[10,11]$. Nanofibers have unique properties such as high surface to mass ratio and flexibility that makes possible to use them as reinforcement of composites. Polymer nanofibers can be applied as a secondary reinforcement of hybrid composites, where thin fiber meshes are applied as interleaves. Such application of electrospun nanofibers was patented by Dzenis and Reneker [12]. Thin nanofiber interleaves of several micrometres can hinder crack propagation and moreover it seems that the thickness - and therefore the in- plane properties - of the laminate are not altered significantly. Nanofiber layers can increase both the quasi-static and impact [13-15] performance of composites. The appropriate pressure and material selection is crucial for achieving a significant improvement in interlaminar properties. Theoretically, by adjusting the thickness of the interleaves and choosing the appropriate nanofiber material the properties of the composite can be tailored from rigid to tough kind of damage. This effect was demonstrated experimentally for Nylon 6.6 interleaves in $[16,17]$.

The toughening effect of polyacrylonitrile (PAN) nanofibrous interleaves in carbon fiber-reinforced structures was proved in [18]. It was demonstrated that the presence of electrospun PAN nanofibrous interleaves can effectively increase the impact properties of carbon reinforced composites without

\footnotetext{
${ }^{*}$ Corresponding author, e-mail: stepan.lomov@mtm.kuleuven.be (C) BME-PT
} 
compromising their in-plane mechanical properties. This was achieved with low weight fraction of the nanofibers, which do not alter the thickness of the composite laminates. Thicker interleaves may potentially improve the quality of the toughening, but they can significantly alter the thickness of composites, therefore reducing their in-plane strength. The compressibility of fibers and the consequent thickness of composites also influence residual stresses and geometrical unconformities in the produced part $[19,20]$. The present paper investigates how the presence of the interleaves of different areal weight affects compressibility of the fabric layup during manufacturing of the composites and hence the fiber volume fraction attainable at the given processing pressure.

Fibrous nano-additions, even in small amounts, can significantly increase the compression resistance of fabric layups. This was demonstrated for the case of carbon nanotubes (CNT) grown on fibers (woven fabrics), both for random and aligned CNT forests [21-23]. For the CNT load of about $10 \mathrm{~g} / \mathrm{m}^{2}$ per fabric layer the layup thickness increases up to $20 \%$ for a random CNT forest and up to $30 \%$ for an aligned CNT forest at the same compaction pressure. This increase of the layup thickness decreases proportionally the fiber volume fraction in the composite laminate, significantly compromising its in-plane mechanical properties. This phenomenon is also observed in fabrics without nano-additions [24, 25]. The high compression resistance of the CNT forests, which is transformed in the CNT-grafted fabric in the low compressibility of the layups, is explained in $[26,27]$ by high contacts density in a CNT forest and high resistance of the stiff CNTs to bending.

Compression behavior of random fibrous assemblies is controlled by a number of factors as fiber bending rigidity and friction and fiber orientation and density in an assembly. Descriptive and to certain extent predictive theories for compression resistance can be found in $[28,29]$. So far as the listed properties of two different fiber assemblies are close, one can expect that the compression response of these assemblies is close as well; the differences of these properties lead to different compression resistance.

Electrospun nanofibers have larger bending rigidity than CNTs. Bending rigidity of a typical multiwall CNT with diameter of $20 \mathrm{~nm}, 20$ walls and the wall Young modulus of $1000 \mathrm{GPa}$ is estimated as
$1 \cdot 10^{-20} \mathrm{~N} \cdot \mathrm{m}^{2}$ [26]. Bending rigidity of a typical PAN nano-fiber with diameter of $200 \mathrm{~nm}$ [20] and Young modulus of $8 \mathrm{GPa}[30]$ is estimated as $1 \cdot 10^{-17} \mathrm{~N} \cdot \mathrm{m}^{2}$. The larger bending rigidity brings larger compaction resistance. Moreover, the coefficient of friction for PAN fibers (about 0.3 [31]) is much higher than that of CNTs (about $0.005[32,33]$ ), which will also brings higher compaction resistance. However, the orientation distribution of PAN fibers in an interleave is close to in-plane, whilst CNTs' orientation distribution in a forest grown on the fibers is either close to being spatially uniform or to radial alignment. Also the number of contacts per unit volume between the PAN fibers is much lower than in a CNT forest with the same areal density due to larger diameter of the PAN fibers. These factors (flat orientation and lower number of contacts) decrease the compaction resistance of a PAN nano-fiber interleave or veil in comparison with CNT forests. The two competing tendencies make it difficult to predict a priori, whether the compaction resistance of fabrics with PAN nanofiber interleaves will follow the same trend as of the previously studied fabrics with grown CNTs, and whether the fiber volume fraction of laminates with PAN nanofiber interleaves will be significantly compromised for higher nanofiber contents. The present paper seeks an experimental answer to this question. We will see that the compression resistance of carbon fabrics is affected by the presence of PAN nanofiber interleaves less than by CNT growth.

\section{Materials and sample preparation}

Nanofibers are generated from polyacrilonitrile (PAN) powder dissolved in dimethyl-formamide (DMF) in a concentration of 12 mass\%. The PAN was supplied by a carbon fiber manufacturer that wished to be anonymous, while DMF was a product of Molar Chemicals, Hungary.

The nanofibers were produced by a novel method, called corona-electrospinning developed by Molnár et al. [34]. The schematic drawing of the electrospinning setup can be seen in Figure 1. The setup consists of a high voltage power supply, a rotating needleless spinneret, a sheet metal collector electrode, a solution feed unit and moving belt that is just in front of the collector screen and therefore nanofibers are deposed on the surface of this substrate making possible the continuous nanofiber production. 


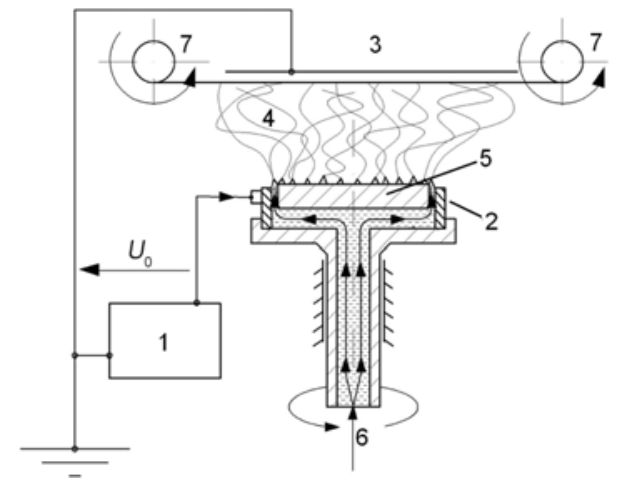

Figure 1. The applied electrospinning setup, 1: high voltage power supply, 2: circular electrode having sharp edge, 3: grounded collector screen, 4: fiber formation space, 5: lid, 6: solution feed, 7: traction of the collector textile (coating of the carbon fabrics takes place between these rolls) [34]

The method compared to the single-needle setup has a high throughput. The solution is continuously fed through a circular-shaped duct that is bounded by a sharp metal edge from outside and a plastic lid from inside. High local field strength is formed along the sharp metal edge and Taylor-cones are formed from the liquid contacting this edge. The forming cones along the circular electrode look like a medieval crown and thus the name was given for the technology. The slight rotation of the whole spinneret is necessary to homogeneously disperse the solution material along the electrode hence avoiding the local overflow of the solution.

In our experiments the corona-spinneret was an aluminum-based construction having a diameter of $100 \mathrm{~mm}$. The rotation speed was $120 \mathrm{rpm}$. MA2000 NT 65/P (Hungary) type power supply was used to generate the necessary high voltage of $55 \mathrm{kV}$ for fiber formation. Solution was fed through a syringe pump (Aitecs SEP-10P Plus, Lithuania) with a flow rate of $30 \mathrm{~mL} / \mathrm{h}$. To remove the evaporated solvent from the electrospinning space, ventilation was applied. Nanofibers in homogeneous layers were produced.

PAN nanofiber veils were deposited on a stationary substrate $-0.2 \mathrm{~mm}$ thick aluminum sheet with deposition times of $15 \mathrm{~min}\left(3.64 \mathrm{~g} / \mathrm{m}^{2}\right), 30 \mathrm{~min}$ $\left(5.80 \mathrm{~g} / \mathrm{m}^{2}\right), 60 \mathrm{~min}\left(17.8 \mathrm{~g} / \mathrm{m}^{2}\right), 120 \mathrm{~min}\left(52.8 \mathrm{~g} / \mathrm{m}^{2}\right)$. The values in brackets indicate areal density of the veils, measured on a $100 \times 100 \mathrm{~mm}$ area. The scatter of these values is about $1 \mathrm{~g} / \mathrm{m}^{2}$ (standard deviation in five measurements). The areal density does not depend linearly on deposition time because it takes time to homogeneously disperse the liquid along the long electrospinning edge. After the starting process a continuous production is developed. In the case of the 15 and 30 min samples the ventilation was used in swinging mode to achieve a more homogeneous deposition of the fibers. That leads to an increased deposition area of the fibers resulting in smaller areal densities.

In order to investigate the interaction of classical fiber and nanofiber layers carbon fabric was coated by nanofibers. Sigratex KDL 8003 (SGL Technologies $\mathrm{GmbH}$, Germany), a plain weave carbon fabric with an areal density of $200 \mathrm{~g} / \mathrm{m}^{2}$ was chosen for these experiments. The carbon fabrics were cut into $200 \mathrm{~mm}$ wide strips. The carbon fabric was coated directly by nanofibers as the carbon fabric layer was attached to the rollers (according to Figure 1.) and continuous traction speed of $200 \mathrm{~mm} / \mathrm{min}$ was applied. In that sense the nanofibers are deposed on

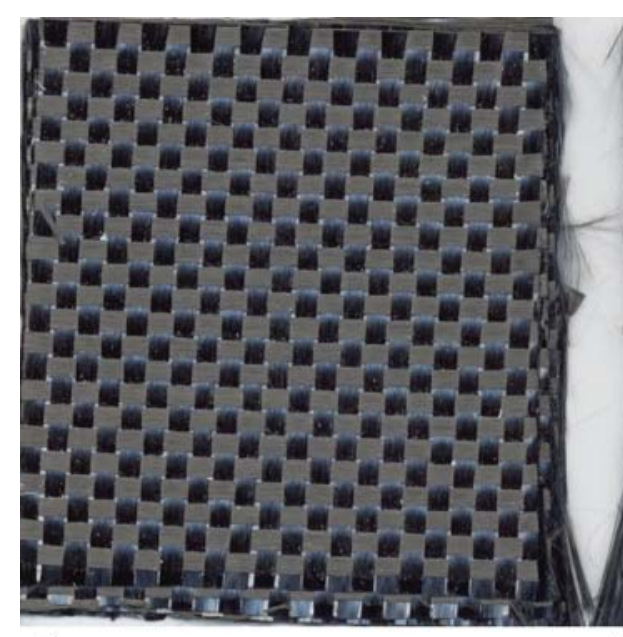

a)

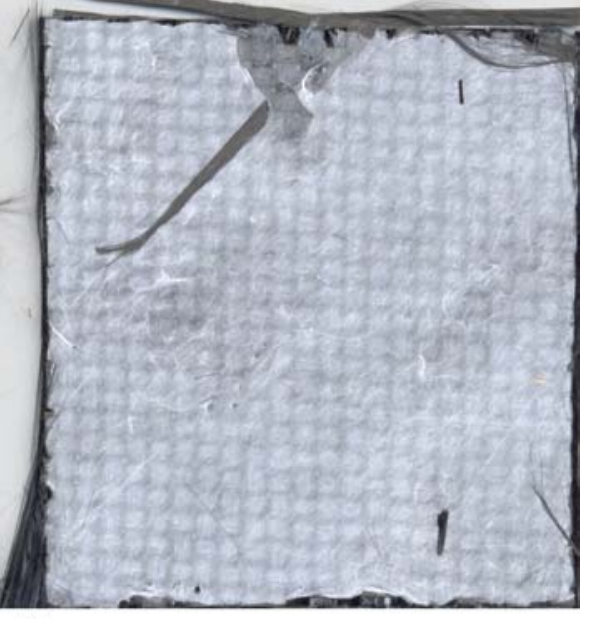

b)

Figure 2. Carbon plain weave fabric without (a) and with (b) PAN nanofiber veil 
Table 1. Parameters of the carbon fabric and PAN nanofibers

\begin{tabular}{|l|c|l|c|}
\hline \multicolumn{2}{|c|}{ Fabric } & \multicolumn{2}{c|}{ Nanofibers } \\
\cline { 1 - 2 } ID & $\begin{array}{c}\text { Sigratex KDL } \\
8003\end{array}$ & Material & PAN \\
\hline Fibers & HT carbon 3K & Diameter [nm] & $195 \pm 46$ \\
\hline $\begin{array}{l}\text { Fabric areal } \\
\text { density }\left[\mathrm{g} / \mathrm{m}^{2}\right]\end{array}$ & 200 & $\begin{array}{l}\text { Interleave } / \mathrm{veil} \\
\text { areal density }\left[\mathrm{g} / \mathrm{m}^{2}\right]\end{array}$ & $5 \ldots 30$ \\
\cline { 1 - 2 } $\begin{array}{l}\text { Yarn linear } \\
\text { density [tex] }\end{array}$ & 200 & & \\
\cline { 1 - 2 } $\begin{array}{l}\text { Ends/picks } \\
\text { count [yarns/cm] }\end{array}$ & 5 & & \\
\hline
\end{tabular}

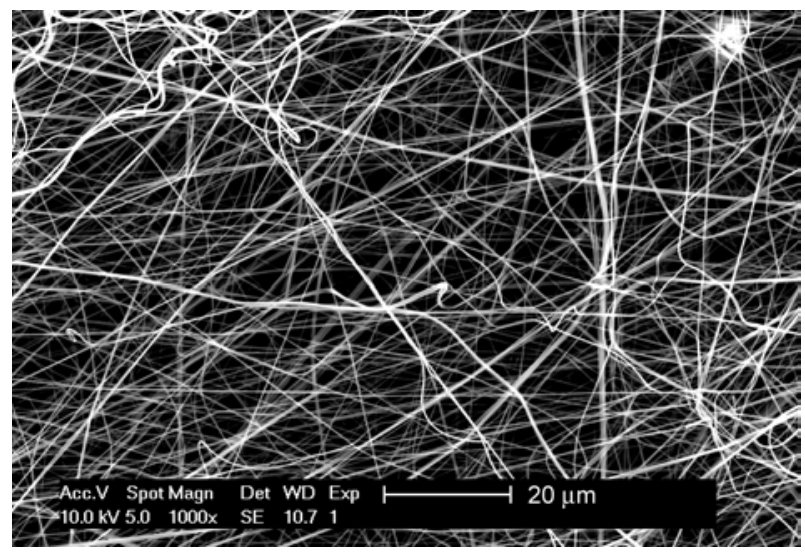

Figure 3. SEM image of PAN nanofiber veil

the surface of the continuously moving carbon fabric stripes. Different coating thicknesses were produced as the carbon fiber material was passing through the equipment 1,2 and 4 times, respectively. At the compression experiments a reference fabric was also applied (Figure 2). The main data of the applied materials is summarized in Table 1. Figure 2 shows a surface view of the fabric before and after coating, and Figure 3 - a fabric sample with veil.

\section{Test method}

The test method was the same as the one which was used for measurement of compressibility of fabrics with grown CNT forests [21, 22] where the reader is referred to for more detailed description. Figure 4 shows the test setup as well as representative compression data for four plies of virgin cloth over three loading cycles. In the data in Figure 4, and throughout the manuscript, the sample thickness $(h)$ is normalized by the number of plies so that single- and stacked-ply data can be compared directly. Figure $4 \mathrm{~b}$ shows a nonlinear stiffening response $h=h(p)$, where $p$ is the applied pressure, with significant hysteresis. The fiber volume fraction is directly proportional to the thickness. A displacement-controlled testing machine Instron 4467 was used with a $1 \mathrm{kN}$ load cell at a test speed of $1 \mathrm{~mm} / \mathrm{min}$. Selfaligning pivots were used (Figure 4a). The compression plate diameter was $70 \mathrm{~mm}$. The specimens of the veils were cut to the size approximately $100 \times 100 \mathrm{~mm}$, and positioned for compression in such a way that the compression plate was situated in the middle of the specimen. To get to higher pressures for fabric and fabric+veil specimens, they were cut to the size of approximatively $50 \times 50 \mathrm{~mm}$, which were placed in the middle of the compression plate. Three tests were first performed without a specimen to establish the reference curves 'displacement of

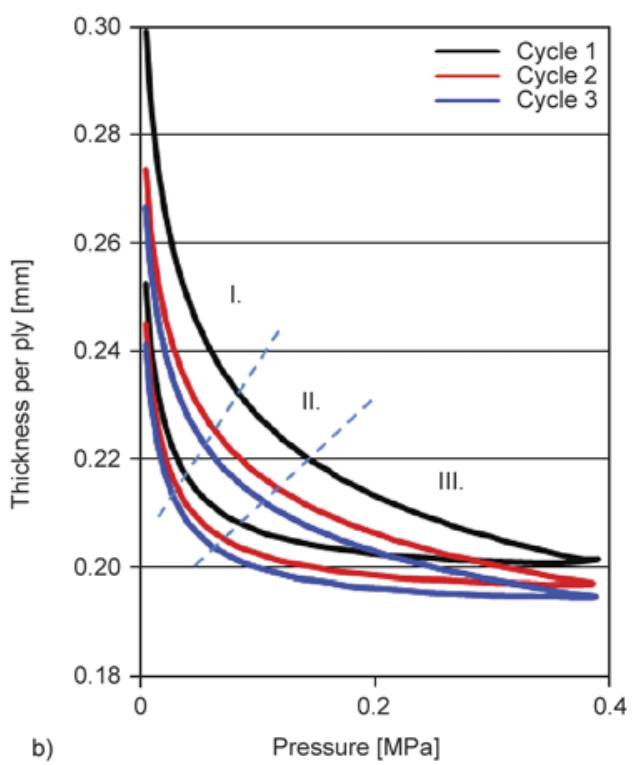

Figure 4. Compression test setup (a) and typical test results (b) - compression curves for compression of four layers of fabric without interleaves 
the head $x$ vs pressure' $x_{0}=x_{0}(p)$, so that the specimen thickness was calculated as $h(p)=x(p)-x_{0}(p)$, where $x$ is the measured head displacement with the specimen. The reference curves were re-registered after testing, to confirm the stability of the measurement. The neat veils produced onto the aluminum sheets were tested in compression together with the aluminum substrate; the reference curve $x_{0}(p)$ was determined in compression of an empty aluminum sheet.

One fabric layer and four-ply stacks of fabric were tested to study the nesting effects during the compression. Three successive compression cycles (loading-unloading) were performed for each specimen. For each material type (veils of different areal density; fabrics without nanofibers, one layer and four layers; fabrics with nanofibers interleave, one layer and four layers) five specimens were tested, with the three compression cycles imposed on each specimen.

\section{Results and discussion}

The measured compression diagrams follow patterns typical for compression of fibrous assemblies. The compressibility of random fibrous assemblies in general (non-woven textiles, bulk fibers like wool) is well understood. A typical pressure vs. thickness diagram, shown in Figure 4b, demonstrate the same features as are outlined in [22] for a general case of compression of a textile. Figure $4 \mathrm{~b}$ shows three successive cycles of compression of the same sample. For each cycle, region I of the diagram (low pressure) is controlled by change of the fiber crimp, and the low compression resistance is given by low bending resistance of the fibers. Region II is intermediate. In the high pressure region III the fibers come close together, the number of contacts of between them increases dramatically, there is no more freedom for the fibers to bend, and the resistance to compression is more and more defined by high Hertzian contact forces rather than by bending of the fibers. Fibers themselves can be considered as not compressible in the range of pressure used in composite manufacturing. If the compaction load is released and then applied again in a second, third etc. cycle, then a certain part of the deformation is not recovered when the load is released, and the thickness under given load decreases for each successive cycle. This hysteresis behavior is studied in [28]. Typically after the third cycle the differences between the sub- sequent cycles become negligible. For typical composite preforms the practically interesting region of the final state of the preform on the compression diagram is shown in Figure $4 \mathrm{~b}$ by the rectangle. To reach this range, a typical assembly has to be compacted into regions II-III of the diagram, with pressure from the vacuum range $(0.8 \ldots 1.0 \mathrm{bar})$ up to several bars.

\subsection{Compressibility of PAN nanofiber veils}

Figure 5 shows compression diagrams of PAN nanofiber veils (only curves for the veil deposition time 15 and 120 min are shown). Five tests, each with three compression cycles, were done for every variant of the nanofiber deposition time. For better clarity only the 3 most different characteristics are depicted.

One can note a significant unevenness of the veils: the veil thickness at the maximum pressure of $0.23 \mathrm{MPa}$ can be different by two or even three times for the same veil deposition time. All veils show a distinct 'sticking' behavior. After the first compression the compressibility of the veil is drastically decreased, especially for thinner veils ( $15 \mathrm{~min}$, also observed for 30 min case). Significant hysteresis is observed for the first compression cycle for thinner veils and for all compression cycles for thicker veils (120 min, also observed for $60 \mathrm{~min}$ ).

In spite of the high scatter, a clear trend of the compressibility can be revealed, if one considers the veil thickness at a given pressure. A natural choice of the pressure level for such a comparison is $0.1 \mathrm{MPa}$ ( 1 bar), which is characteristic for vacuum assisted composite manufacturing. Thickness of a material at $0.1 \mathrm{MPa}$ pressure in a loading half-cycle will be called in this paper ' 1 bar thickness'. Figure 6 shows 1 bar veil thickness as a function of veil areal density.

1 bar veil thickness exhibits large scatter for the first compression cycle and stabilizes for the subsequent cycles. The dependency ' 1 bar veil thickness - veil areal density' is well approximated by a logarithmic function. One can expect that because of an additive nature of depositing the nanofibers the veil thickness should be proportional to the veil areal density. This is not the case. A material with higher areal density densifies more effectively. One can speculate that this reflects the fact that during elecrospinning the coverage of the surface by nanofibers is higher for longer deposition times. Fibers try to fill the sur- 

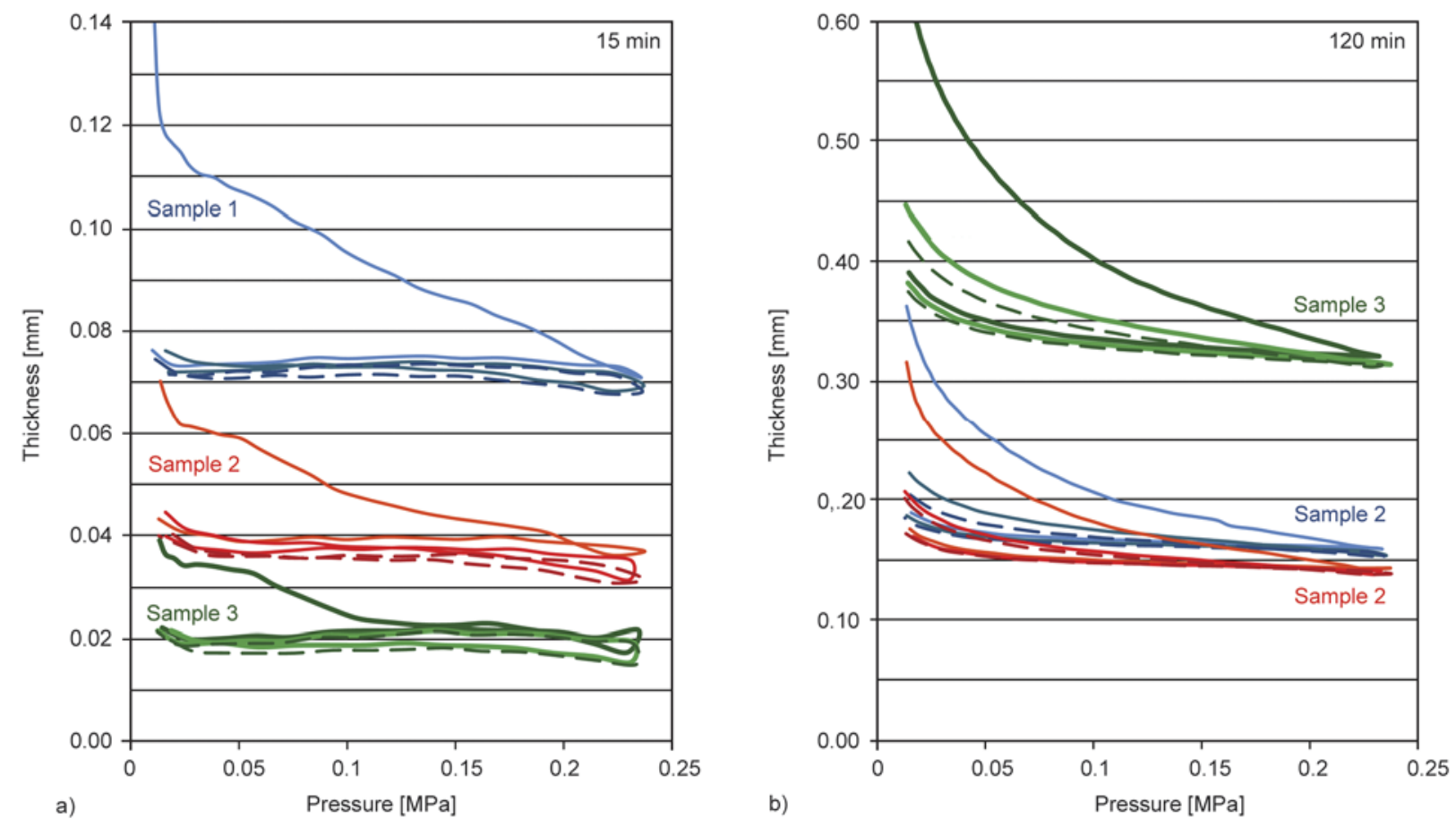

Figure 5. Compression diagrams of PAN nanofiber veils. Veil deposition time: (a) $15 \mathrm{~min}$, (b) $120 \mathrm{~min}$.

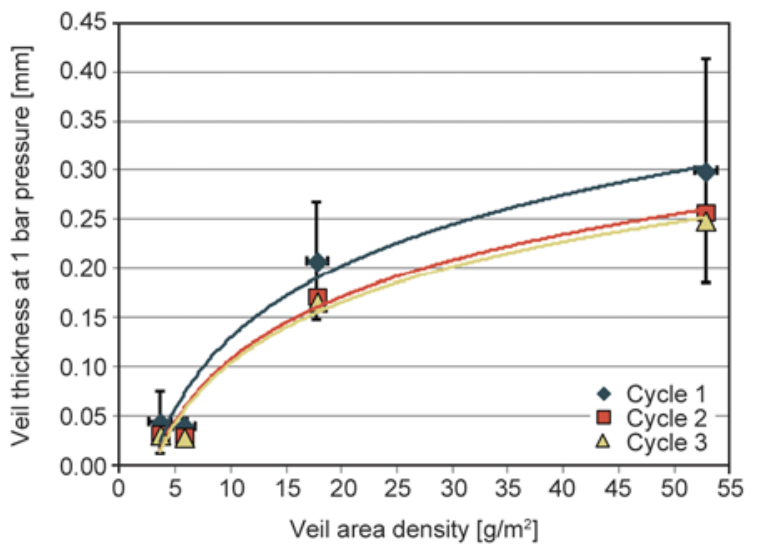

Figure 6. Veil thickness at pressure 1 bar in function of the veil areal density. Error bars show standard deviation in five tests (logarithmic fit was applied).

face first, and then start building up thickness of the veil.

\subsection{Compressibility of woven laminates with interleaves}

Figure 7 shows compression diagrams obtained from tests with woven laminates with interleaves, as well as compression diagrams for the non-interleaved fabric. The diagrams depict dependency of the thickness of one layer on the applied pressure, for tests with one and four layers in three successive compression cycles. Five diagrams for each variant (three cycles each) of the material are shown together, to give an impression of the scatter of the compaction response.
Each of these five three-cycle diagrams have the same qualitative characteristic shape as shown in Figure $4 b$.

Standard features of the textile compaction are evidenced by the diagrams for non-interleaved fabric laminates (Figure 7a, 7b, see also Figure 4b): characteristic fast stiffening of the compressed fabric; significant decrease of the compacted stiffness in the second compaction cycle in comparison with the first cycle at the same pressure, and stabilization of the thickness at the third cycle; nesting, i.e. less thickness per one ply in compaction of four fabric plies in comparison with compaction of one ply.

When nanofiber interleaves are added, the compression diagrams are shifted up (compare Figure 7a, 7c, $7 \mathrm{e}$ or Figure $7 \mathrm{~b}, 7 \mathrm{~d}, 7 \mathrm{f}$ ); the thickness of the fabric ply or laminate at a given pressure increases. The increase looks marginal for $5 \mathrm{~g} / \mathrm{m}^{2}$ veil areal density, but becomes considerable for $28 \mathrm{~g} / \mathrm{m}^{2}$. The nesting is present also in the case of the presence of the nanofiber interleaves, as well as in their absence (compare Figure $7 \mathrm{a}-7 \mathrm{~b}, 7 \mathrm{c}-7 \mathrm{~d}$ and $7 \mathrm{e}-7 \mathrm{f})$. To quantify this behavior, the 1 bar fabric ply thickness with and without nanofiber interleaves is considered.

Figure 8a and 8b shows dependency of the 1 bar ply thickness of the areal density of the interleave in one ply. The steady increase of the ply thickness is observed. The rate of increase can be roughly estimated as $3 \mu \mathrm{m}$ thickness increase per $1 \mathrm{~g} / \mathrm{m}^{2}$ increase 

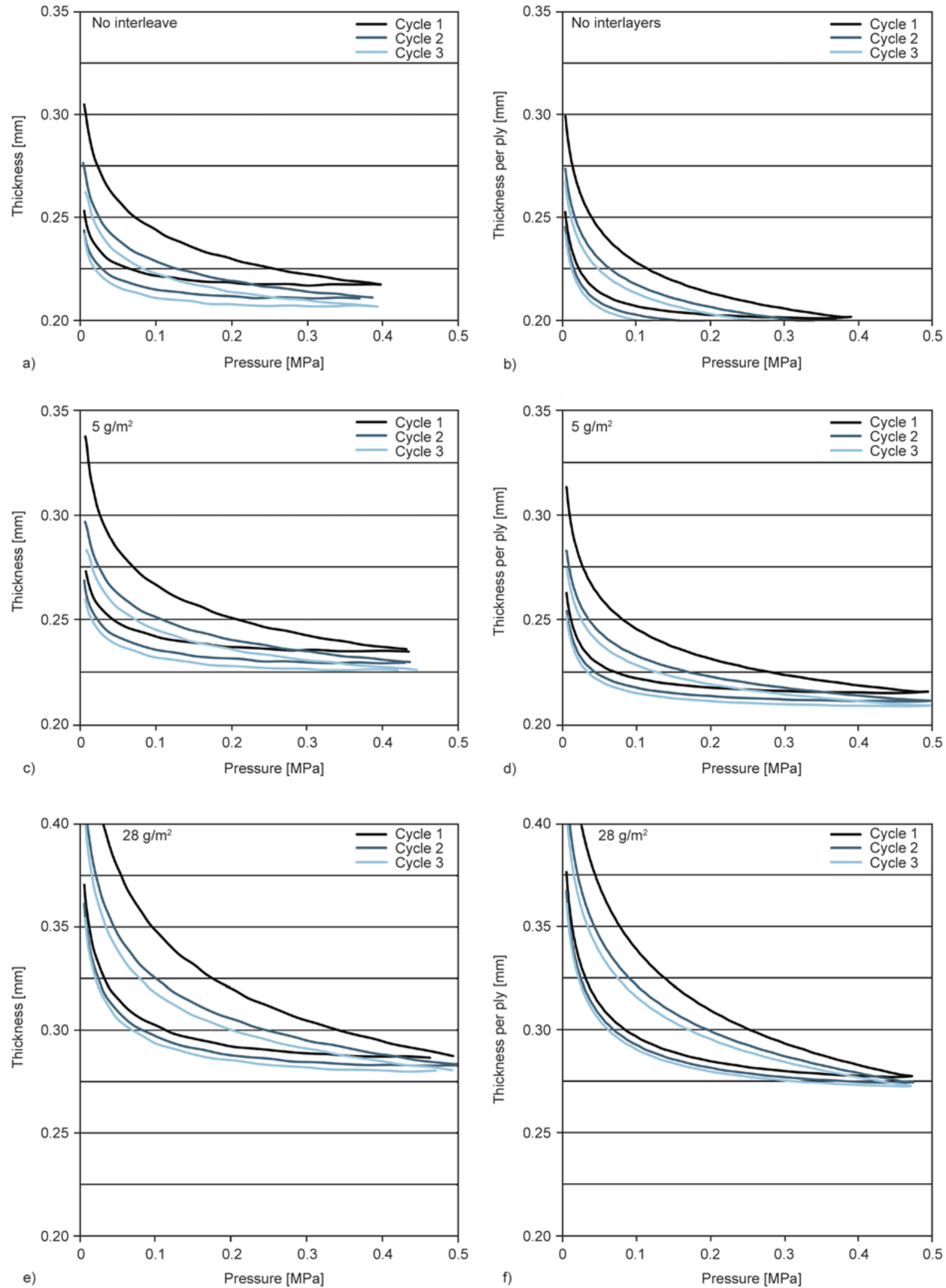

Figure 7. Compression diagrams of carbon woven fabrics with interleaves of PAN nanoveils: thickness of one ply versus pressure. Left column (a, c, e): compression of one fabric ply, right column (b, d, f): compression of four plies. Veil interleave average areal density per ply is shown on the graphs. Diagrams of the most typical curve of the five tests and three compression cycles, are shown in each graph, respectively. 

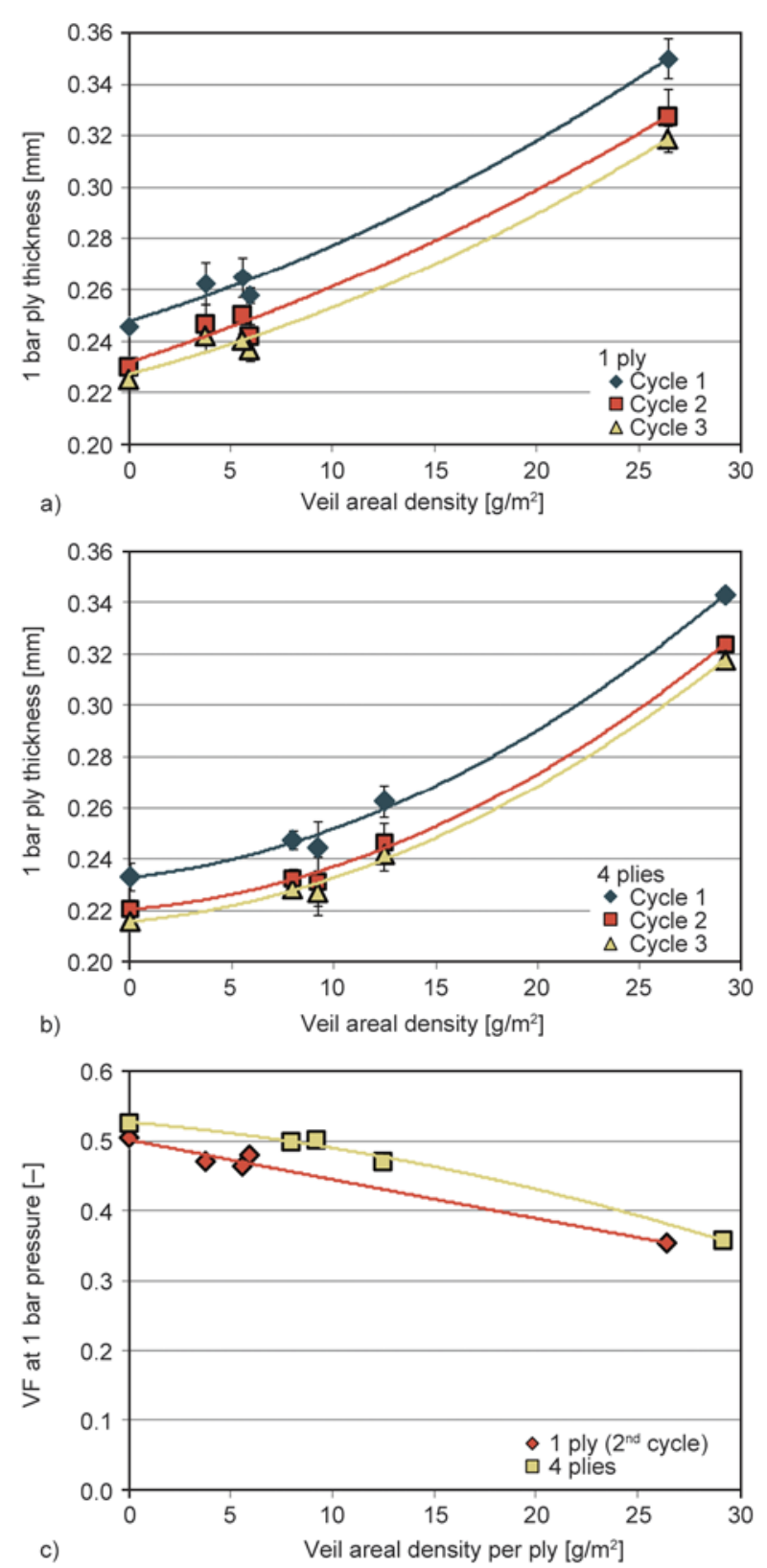

Figure 8. 1 bar ply thickness of carbon woven laminates and fiber volume fraction at 1 bar pressure as functions of the veil areal density: (a) thickness, compression of one ply; (b) thickness, compression of four plies; (c) fiber volume fraction $(V F)$

of the veil areal density. Interestingly in the range of areal density up to $30 \mathrm{~g} / \mathrm{m}^{2}$ this rate is much smaller than the increase of the 1 bar thickness of the veil itself, compressed without fabric, cf. Figure 6 . This phenomenon will be quantified in the next sub-section.

Increase of the laminate thickness leads to decrease of the fiber volume fraction in the consolidated composite. Figure $8 \mathrm{c}$ shows dependency of the $1 \mathrm{bar}$ fiber volume fraction on the nanofibers interleave areal density for the second compression cycle. The second cycle was chosen as a cycle giving a representative condition of the laminate layers; the reader is referred to [18] for more extensive discussion of this choice. The fiber volume fraction $V F$ was calculated based on the laminate thickness per one ply $t_{1}$ as shown by Equation (1):

$$
V F=\frac{m}{t_{1} \rho}
$$

where $m$ is the areal density of the fabric ply, $\rho$ is the carbon fiber density. As it is seen from Figure 8c, up to the interleave areal density of $10 \mathrm{~g} / \mathrm{m}^{2}$ per fabric layer the fiber volume fraction for a four-ply laminate (this is a practically important case) stays over $50 \%$, with the fiber volume fraction of the laminate without nanofibers being $53 \%$. Interleave areal density up to $10 \mathrm{~g} / \mathrm{m}^{2}$ can be considered as a practically admissible values. The dependency of $V F$ on the interleave areal density is almost linear. It is remarkable that the nesting intensity defined by Equation (2), i.e., the ratio:

$k=\frac{t_{1}(1)-t_{1}(4)}{t_{1}(1)}$

where $t_{1}(N)$ is thickness of one ply in an $N$-plies laminate, stays the same, $k \cong 0.12$ with increase of the interleave areal density. The fabric layers 'feel' the surface relief of one another in spite of the presence of nanofibers between them. This may point to penetration of the nanofibers inside the fabric plies, which will be supported by the observations in the next sub-section.

\subsection{Nanofibers veil thickness and the added thickness of nanofibers interleave}

Figure 9 compares nanofibers 1 bar veil thickness, which was reported in Section 4.1, with the added thickness of nanofibers interleave, calculated based on the measurements of the laminate thickness reported in Section 4.2. The latter for a given compaction pressure (1 bar) is calculated as shown by Equation (3):

$t_{\mathrm{CNF}}=t_{1}^{1-\mathrm{NF}}-t_{1}^{1}$

where $t_{1}^{1}$ and $t_{1}^{1-\mathrm{NF}}$ are thicknesses per one ply of a laminate with and without nanofiber interleaves at the same compaction pressure. As it is seen from Figure 9 , the values of $t_{\text {nanofibers }}$ in laminates and even in compression of one ply of the fabric with a veil 


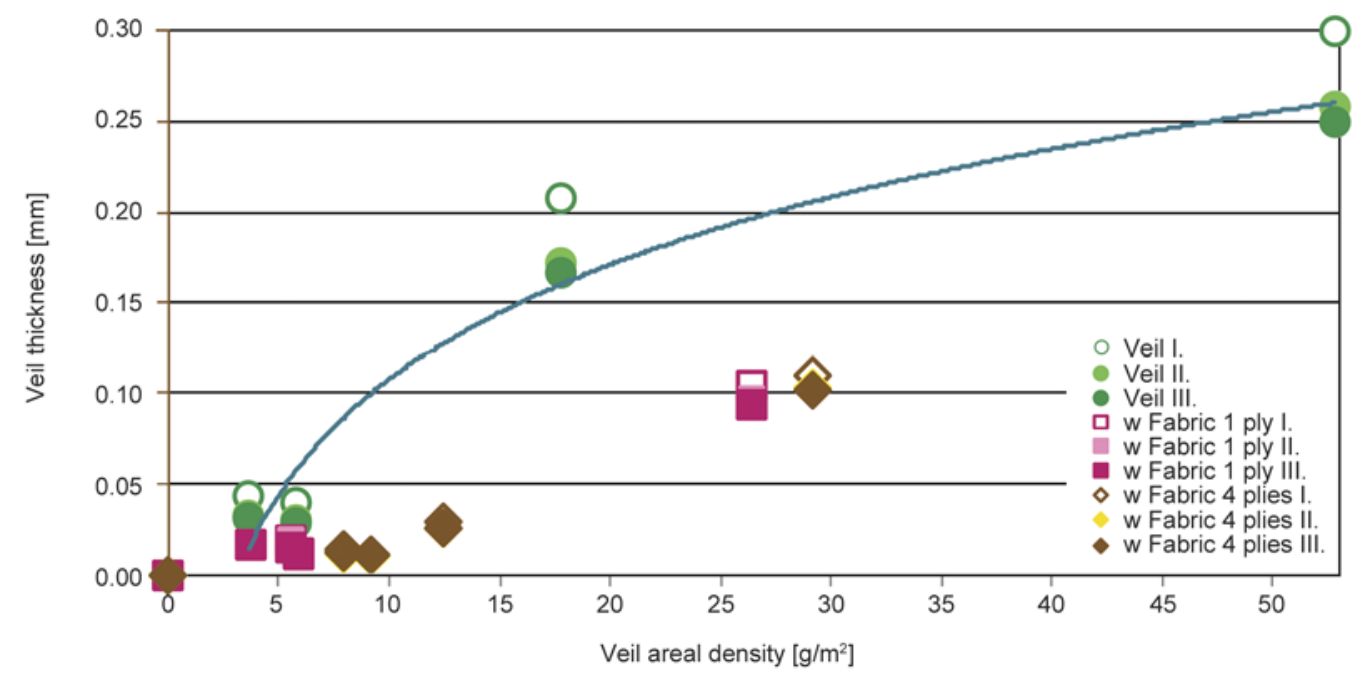

Figure 9. 1 bar veil thickness (average values) as a function of the veil areal density, for the veil itself and veils inside interleaved fabric laminates

on its surface are much smaller that free nanofibers veil thickness for the same veil areal density and the same applied pressure of 1 bar. The nanofibers veil thickness is reduced roughly twice.

A possible interpretation of this fact is that nanofibers penetrate inside the fabric during compaction, which is supported by the measurements of the nesting effect discussed above. This suspected interpenetration of nanofibers inside fabric layers can serve in advantage for increasing delamination resistance, potentially increasing the bridging effect of the interleave by their stronger interaction with fibers in the yarns - a subject worth investigating in future work.

\section{Conclusions}

Nanofiber interleaves in woven fabric laminates decrease compressibility of the laminate, increasing the laminate thickness for a given pressure and correspondingly decreasing fiber volume fraction in the consolidated laminate. The fiber volume fraction decreases almost linearly with the increase of the nanofibers areal density. However, up to areal density of the interleaves of $10 \mathrm{~g} / \mathrm{m}^{2}$ the decrease of the fiber volume fraction is below $3 \%$ and is practically acceptable.

The thickness of the nanofibers interlayers inside a woven laminate at a given pressure is twice smaller, than the thickness of CNT veils with the same areal density and under the same compacting pressure. This fact points to strong interference between the interleaves and the carbon reinforcement, which can lead to effective toughness improvement of the composite.

\section{Acknowledgements}

The work in KU Leuven was a part of a project GOA/10/ 004 'New model-based concepts for nano-engineered polymer composites', funded by the Research Council of K.U. Leuven. The research in Budapest was supported by the Hungarian Research Fund (OTKA K100949).

\section{References}

[1] Jing X., Mi H-Y., Salick M. R., Cordie T. M., Peng X-F., Turng L-S.: Electrospinning thermoplastic polyurethane/ graphene oxide scaffolds for small diameter vascular graft applications. Materials Science and Engineering: C, 49, 40-50 (2015).

DOI: $10.1016 /$ j.msec.2014.12.060

[2] Erben J., Pilarova K., Sanetrnik F., Chvojka J., Jencova V., Blazkova L., Havlicek J., Novak O., Mikes P., Prosecka E., Lukas D., Kostakova E. K.: The combination of meltblown and electrospinning for bone tissue engineering. Materials Letters, 143, 172-176 (2015). DOI: $10.1016 /$ j.matlet.2014.12.100

[3] Braghirolli D. I., Steffens D., Pranke P.: Electrospinning for regenerative medicine: A review of the main topics. Drug Discovery Today, 19, 743-753 (2014). DOI: 10.1016/j.drudis.2014.03.024

[4] Nagy Zs. K., Balogh A., Vajna B., Farkas A., Pátyi G., Kramarics Á., Marosi Gy.: Comparison of electrospun and extruded Soluplus ${ }^{\circledR}$-based solid dosage forms of improved dissolution. Journal of Pharmaceutical Sciences, 101, 322-332 (2012). DOI: $10.1002 / j p s .22731$

[5] Balogh A., Drávavölgyi G., Faragó K., Farkas A., Vigh T., Sóti P. L., Wagner I., Madarász J., Pataki H., Marosi Gy., Nagy Zs. K.: Plasticized drug-loaded melt electrospun polymer mats: Characterization, thermal degradation, and release kinetics. Journal of Pharmaceutical Sciences, 103, 1278-1287 (2014).

DOI: $10.1002 / j p s .23904$ 
[6] Orriach-Fernández J. F., Medina-Castillo A. L., DíazGómez J. E., Muñoz de la Peña A., Fernández-Sánchez J. F., Fernández-Gutiérrez A.: A sensing microfibre mat produced by electrospinning for the turn-on luminescence determination of $\mathrm{Hg}^{2+}$ in water samples. Sensors and Actuators B: Chemical, 195, 8-14 (2014).

DOI: $10.1016 /$ j.snb.2014.01.010

[7] Ahmed F. E., Lalia B. S., Hashaikeh R.: A review on electrospinning for membrane fabrication: Challenges and applications. Desalination, 356, 15-30 (2015).

DOI: $10.1016 /$ j.desal.2014.09.033

[8] Carroll T., Booker N. A., Meier-Haack J.: Polyelectrolyte-grafted microfiltration membranes to control fouling by natural organic matter in drinking water. Journal of Membrane Science, 203, 3-13 (2002). DOI: $10.1016 / \mathrm{S} 0376-7388(01) 00701-3$

[9] Sang Y., Gu Q., Sun T., Li F., Liang C.: Filtration by a novel nanofiber membrane and alumina adsorption to remove copper(II) from groundwater. Journal of Hazardous Materials, 153, 860-866 (2008).

DOI: $10.1016 /$ j.jhazmat.2007.09.035

[10] Huang Z-M., Zhang Y-Z., Kotaki M., Ramakrishna S.: A review on polymer nanofibers by electrospinning and their applications in nanocomposites. Composites Science and Technology, 63, 2223-2253 (2003).

DOI: $10.1016 / \mathrm{S} 0266-3538(03) 00178-7$

[11] Andrady A. L.: Science and technology of polymer nanofibers. Wiley, New Jersey (2008).

[12] Dzenis Y. A., Reneker D. H.: Delamination resistant composites prepared by small diameter fiber reinforcement at ply interfaces. U.S. Patent 6265333, USA (2001).

[13] Kelkar A. D., Mohan R., Bolick R., Shendokar S.: Effect of nanoparticles and nanofibers on Mode I fracture toughness of fiber glass reinforced polymeric matrix composites. Materials Science and Engineering: B, 168, 85-89 (2010).

DOI: $10.1016 / \mathrm{j} . \mathrm{mseb} .2010 .01 .015$

[14] Liu L., Huang Z-M., He C. L., Han X. J.: Mechanical performance of laminated composites incorporated with nanofibrous membranes. Materials Science and Engineering: A, 435-436, 309-317 (2006).

DOI: $10.1016 / \mathrm{j} . \mathrm{msea} .2006 .07 .064$

[15] Zhang J., Lin T., Wang X.: Electrospun nanofibre toughened carbon/epoxy composites: Effects of polyetherketone cardo (PEK-C) nanofibre diameter and interlayer thickness. Composites Science and Technology, 70, 1660-1666 (2010).

DOI: 10.1016/j.compscitech.2010.06.019

[16] Palazzetti R., Yan X., Zucchelli A.: Influence of geometrical features of electrospun nylon 6,6 interleave on the CFRP laminates mechanical properties. Polymer Composites, 35, 137-150 (2014).

DOI: $10.1002 /$ pc. 22643
[17] Palazzetti R., Zucchelli A., Trendafilova I.: The selfreinforcing effect of Nylon 6,6 nano-fibres on CFRP laminates subjected to low velocity impact. Composite Structures, 106, 661-671 (2013). DOI: 10.1016/j.compstruct.2013.07.021

[18] Molnár K., Kostáková E., Mészáros L.: The effect of needleless electrospun nanofibrous interleaves on mechanical properties of carbon fabrics/epoxy laminates. Express Polymer Letters, 8, 62-72 (2014).

DOI: $10.3144 /$ expresspolymlett.2014.8

[19] Sorrentino L., Bellini C.: Compaction influence on spring-in of thin composite parts: Experimental and numerical results. Journal of Composite Materials, 49, 2149-2158 (2014).

DOI: $10.1177 / 0021998314542362$

[20] Ersoy N., Garstka T., Potter K., Wisnom M. R., Porter D., Stringer G.: Modelling of the spring-in phenomenon in curved parts made of a thermosetting composite. Composites Part A: Applied Science and Manufacturing, 41, 410-418 (2010).

DOI: $10.1016 /$ j.compositesa.2009.11.008

[21] Lomov S. V., Gorbatikh L., Houlle M., Kotanjac Z., Koissin V., Vallons K., Verpoest I.: Compression resistance and hysteresis of carbon fibre tows with grown carbon nanotubes/nanofibres. Composites Science and Technology, 71, 1746-1753 (2011). DOI: 10.1016/j.compscitech.2011.08.007

[22] Lomov S. V., Gorbatikh L., Kotanjac Z., Koissin V., Houlle M., Rochez O., Karahan M., Mezzo L., Verpoest I.: Compressibility of carbon woven fabric with carbon nanotubes grown on the fibres. Composites Science and Technology, 71, 315-325 (2011). DOI: 10.1016/j.compscitech.2010.11.024

[23] Lomov S. V., Wicks S., Gorbatikh L., Verpoest I., Wardle B. L.: Compressibility of nanofibre-grafted alumina fabric and yarns: Aligned carbon nanotube forests. Composites Science and Technology, 90, 57-66 (2014).

DOI: 10.1016/j.compscitech.2013.10.017

[24] Sorrentino L., Bellini C.: Analysis of laminate thickness influence on compressibility behavior in a rift process. International Journal of Engineering and Technology, 6, 1259-1267 (2014).

[25] Chen Z-R., Ye L.: A micromechanical compaction model for woven fabric preforms. Part II: Multilayer. Composites Science and Technology, 66, 3263-3272 (2006).

DOI: 10.1016/j.compscitech.2005.07.010

[26] Lomov S. V., Gorbatikh L., Verpoest I.: A model for the compression of a random assembly of carbon nanotubes. Carbon, 49, 2079-2091 (2011). DOI: 10.1016/j.carbon.2011.01.043

[27] Lomov S. V., L. Gorbatikh V. I., Verpoest I.: Compression behaviour of a fibre bundle with grafted carbon nanotubes. Carbon, 49, 4458-4465 (2011).

DOI: 10.1016/j.carbon.2011.06.044 
[28] Carnaby G. A., Pan N.: Theory of the compression hysteresis of fibrous assemblies. Textile Research Journal, 59, 275-284 (1989).

DOI: $10.1177 / 004051758905900505$

[29] Komori T., Itoh M., Takaku A.: A model analysis of the compressibility of fiber assemblies. Textile Research Journal, 62, 567-574 (1992).

DOI: $10.1177 / 004051759206201002$

[30] Mikolajczyk T., Rabiej S., Szparaga G., Boguń M., Fraczek-Szczypta A., Błażewicz S.: Strength properties of polyacrylonitrile (PAN) fibres modified with carbon nanotubes with respect to their porous and supramolecular structure. Fibres and Textiles in Eastern Europe, 17, 13-20 (2009).

[31] Svetnickienè V., Čiukas R.: Technical and classical yarns friction properties investigation. Mechanika, 60, 54-58 (2006).
[32] Bhushan B., Ling X., Jungen A., Hierold C.: Adhesion and friction of a multiwalled carbon nanotube sliding against single-walled carbon nanotube. Physical Review B, 77, 165428/1-165428/12 (2008). DOI: $10.1103 /$ PhysRevB.77.165428

[33] Falvo M. R., Taylor R. M., Helser A., Chi V., Brooks F. P., Washburn S., Superfine R.: Nanometre-scale rolling and sliding of carbon nanotubes. Nature, 397, 236-238 (1999).

DOI: $10.1038 / 16662$

[34] Molnár K., Nagy Zs. K., Marosi Gy., Mészáros L.: Electrospinning spinneret and modified electrospinning method for producing nanofibers in productive ways. Hungarian patent P1200677, Hungary (2012). 